\title{
Analysis of the heat transfer coefficient during potato frying
}

\author{
Rui M. Costa ${ }^{\text {a }}$, Fernanda A.R. Oliveira ${ }^{b, *}$, Olivia Delaney ${ }^{a}$, Vassilis Gekas ${ }^{\text {c }}$ \\ a Escola Superior de Biotecnologia, Rua Dr António Bernardino de Almeida, 4200 Porto, Portugal \\ ${ }^{\mathrm{b}}$ Instituto Inter-Universitário de Macau, Nape, Lote 18, Rua de Londres, Edf. Tak Ip Plaza P, Macau \\ ${ }^{\mathrm{c}}$ Laboratory of Transport Phenomena and Unit Operations, Department of Environmental Engineering, Technical University of Crete, \\ Polytechneioupolis, 73100 Hania, Greece
}

\begin{abstract}
The objective of this work was to study the dependence of the heat transfer coefficient $(h)$ on the water loss rate of potato during frying. An indirect method was used where a metal piece with the same geometry of the potato pieces was placed on top of various potato samples at different frying times, and its temperature was recorded for 20-30 s. Another method consisted of direct recording of the temperature within a potato slice, close to the surface. Water loss rate was estimated by image analysis of bubbles. After immersion in hot oil, the potato temperature increases and water starts vapourising, leaving the surface in the form of bubbles that flow through the oil. The water loss rate increases until complete drying of the potato surface and then decreases till the end of frying. The $h$ value showed the same behaviour increasing up by two times in relation to the values measured in the absence of bubbling, with maximum values depending on the oil temperature and potato geometry (443-750 $\mathrm{W} \mathrm{m}^{-2} \mathrm{~K}^{-1}$ ). The percentage of heat transferred to the potato that is used for water evaporation showed an increase with time up to complete surface drying.
\end{abstract}

Keywords: Bubbling; Heat transfer; Potato; Frying; Water loss

\begin{tabular}{|c|c|c|}
\hline \multicolumn{3}{|c|}{ Notation } \\
\hline$A$ & surface area & $\mathrm{m}^{2}$ \\
\hline$c_{\mathrm{p}}$ & specific heat & $\mathrm{J} \mathrm{kg}^{-1} \mathrm{~K}^{-1}$ \\
\hline$h$ & heat transfer coefficient & $\mathrm{W} \mathrm{m}^{-2} \mathrm{~K}^{-1}$ \\
\hline $\bar{h}$ & average heat transfer coefficient & $\mathrm{W} \mathrm{m}^{-2} \mathrm{~K}^{-1}$ \\
\hline$k$ & heat conductivity & $\mathrm{W} \mathrm{m}^{-1} \mathrm{~K}^{-1}$ \\
\hline$l$ & half-thickness & $\mathrm{m}$ \\
\hline$L$ & $\begin{array}{l}\text { dimensionless number } \\
\left(L=l \gamma \bar{h} / k_{\mathrm{p}}\right)\end{array}$ & \\
\hline$Q$ & heat transfer rate & $\mathrm{J} \mathrm{s}^{-1}$ \\
\hline$t$ & frying time & $\mathrm{s}$ \\
\hline$T$ & temperature & $\mathrm{K},{ }^{\circ} \mathrm{C}$ \\
\hline V & volume & $\mathrm{m}^{3}$ \\
\hline$\dot{w}$ & water loss rate & $\mathrm{g} \mathrm{s}^{-1}$ or $\mathrm{kg} \mathrm{s}^{-1}$ \\
\hline \multicolumn{3}{|c|}{ Symbols } \\
\hline$\alpha$ & heat diffusivity & $\mathrm{m}^{2} \mathrm{~s}^{-1}$ \\
\hline$\beta$ & $\begin{array}{l}\text { positive root of the equation } \\
\beta_{n} \tan \beta_{n}=L\end{array}$ & \\
\hline$\lambda$ & latent heat & $\mathrm{kJ} \mathrm{kg}^{-1}$ \\
\hline$\gamma$ & $\begin{array}{l}\text { fraction of total heat used for } \\
\text { water evaporation }\end{array}$ & \\
\hline$\rho$ & density & $\mathrm{kg} \mathrm{m}^{-3}$ \\
\hline
\end{tabular}

\footnotetext{
${ }^{*}$ Corresponding author. Tel.: 00-853-7964405; fax: 00-853-725517; e-mail: fernanda@iium.edu.mo
}

$\begin{array}{ll}\text { Subscripts } & \\ \mathrm{e} & \text { evaporation } \\ \mathrm{h} & \text { heating } \\ \mathrm{I} & \text { initial } \\ \mathrm{m} & \text { metal } \\ \mathrm{n} & \text { counting index } \\ \mathrm{o} & \text { oil } \\ \mathrm{p} & \text { potato } \\ \mathrm{s} & \text { surface } \\ \mathrm{t} & \text { total }\end{array}$

\section{Introduction}

During potato frying, heat is transferred from the frying medium to the product surface by convection and from the surface to the inside by conduction. After immersion in the frying medium, a small amount of air occluded within the potato tissue expands and gives rise to the first bubbles that escape from the potato. The potato surface heats up to the wet bulb temperature and water starts vapourising. As frying progresses, the evaporation front moves towards the centre, a surface crust is formed, and eventually the temperature of the potato surface rises to that of the oil.

Vapour bubbling was found to be related to water loss rate and as frying proceeds, bubbling increases to a 
maximum value and then decreases (Costa, Oliveira \& Gekas, 1997). Several authors consider that frying is controlled by the heat transfer between the oil and the potato (Fellows, 1996). Thus, the knowledge of the heat transfer coefficient $(h)$ is most important for process modelling. Miller (1992) studied the influence of temperature, oil type and oil use on the $h$ value and found that the major effect was due to viscosity. Tseng, Moreira and Sun (1996) showed that the use of oil only affected the $h$ value after the discard point, thus no major differences resulting from oil degradation are expected during frying. Many authors consider that the $h$ value is constant during frying or assume two different values, one in the absence of bubbling and another in the bubbling phase (Farkas, 1994). The values reported in the literature vary between 250 and $300 \mathrm{~W} \mathrm{~m}^{-2} \mathrm{~K}^{-1}$ in the temperature range of $170-190^{\circ} \mathrm{C}$ (Miller, Singh \& Farkas, 1994; Tseng et al., 1996), in the absence of bubbling. One may, however, expect that the bubbling effect would change the $h$ value because of the resulting oil agitation; also, if the bubbles are large and do not flow away from the potato surface rapidly, the reverse effect of an additional resistance to heat transfer might occur (Fellows, 1996). Fellows (1996) also refers to a $h$ value that was reported to vary from 250 to $300 \mathrm{~W} \mathrm{~m}^{-2}$ $\mathrm{K}^{-1}$ for the initial heating period to $800-1000 \mathrm{~W} \mathrm{~m}^{-2}$ $\mathrm{K}^{-1}$ for surface boiling conditions. A very limited number of works have been reported concerning the evolution of the heat transfer coefficient during frying. Hubart and Farkas (1998) presented a simplified heat balance to predict the $h$ value along frying, based on measurements of the product surface temperature, oil temperature and water loss rate. The $h$ values reported for frying oil at $180^{\circ} \mathrm{C}$ started at $300 \mathrm{~W} \mathrm{~m}^{-2} \mathrm{~K}$, increased to a maximum value of $1100 \mathrm{~W} \mathrm{~m}^{-2} \mathrm{~K}$ and then decreased below $200 \mathrm{~W} \mathrm{~m}^{-2} \mathrm{~K}$ at $900 \mathrm{~s}$. However, the heat balance used in this work does not take into consideration that some of the heat transferred from the oil is used for heating the potato crust, and predicts that water losses cease when the potato surface reaches the oil temperature, which is not true.

The influence of bubbling on the $h$ value has been thoroughly studied in Chemical and Mechanical Engineering in the cases of pool boiling and flow boiling. Pool boiling theory describes various stages as the difference between the heating source temperature and the liquid saturation temperature increases: natural convection, nucleate boiling, partial film boiling and film boiling (Burmeister, 1983). During nucleation, vapour pockets are formed at preferred sites, with bubbles growing large enough so that the buoyancy forces cause them to detach and flow upward. This is similar to what happens during frying, although in the latter situation the vapour comes from the potato rather than from the heating medium. Furthermore, steady state is never reached because the evaporation conditions change as the temperature and the water content of the food change. As water content decreases, a number of changes occur that will affect the bubble formation, such as the surface roughness, the wetting angle, the number of nucleation sites, the pressure inside the food, etc. Various correlations are presented in the literature to predict the $h$ value in nucleate boiling, based on the knowledge of the thermo-physical properties of the system fluid/ heating source (Burmeister, 1983), but these cannot be directly applied to potato frying. The main objective of this work was to study the dependence of the heat transfer coefficient on the water loss rate during frying of potatoes.

\section{Material and methods}

Frying was performed in an inox bath with 18 -L capacity. The temperature was controlled by a thermostatic head with agitation (Thermomix UB-Braun, Melsungen, Germany) to avoid temperature gradients. The temperature of the bath was controlled to $\pm 0.2^{\circ} \mathrm{C}$. Experiments were conducted at $140^{\circ} \mathrm{C}$ and $180^{\circ} \mathrm{C}$. Potato tubers (CV. Desiree), with $80 \%$ water content were used. Thin slices-crisps $(1.5 \pm 0.1 \mathrm{~mm}$ thickness and $46 \pm 0.5 \mathrm{~mm}$ diameter) were cut with a rotary slicer (Milano, Italy). French-fries $(8.5 \pm 0.5 \times 8.5 \pm 0.5 \times 50 \pm$ $0.5 \mathrm{~mm}^{3}$ ) were cut with a hand French-fry cutter. The density of raw potato was calculated from the weight and volume of potato samples. Samples were weighed in an analytical scale balance (Sartorius, Goettingen, Germany) and volume was determined according to the platform scale technique (Moshenin, 1986) using toluene (Merck, Darmstadt, Germany) as embedding medium. Three replicates were conducted. Sunflower oil of low oleic acid content (ALCO, Porto, Portugal) was used as the frying medium.

\subsection{Indirect method of estimation of the $h$ value}

A steel piece with $10 \times 10 \times 50 \mathrm{~mm}^{3}$ and another steel piece with the same dimensions of the crisps were used to determine the heat transfer coefficient $(h)$ during frying of French-fries and crisps, respectively. Five potato samples were suspended and aligned, side by side, on stainless wires and immersed in the frying bath. A metal piece with the same geometry was immersed and placed 5-10 $\mathrm{mm}$ above the potato slices, so that the hydrodynamic conditions would be similar for both the potato samples and the metal piece (see Fig. 1a). For each measurement, the potato slices were first immersed and then, at selected times, the metal piece was also immersed and the temperature in the centre of the piece was recorded for $20 \mathrm{~s}$ for crisps and $30 \mathrm{~s}$ for Frenchfries. Triplicate runs were performed. The temperature was recorded with a 1-mm diameter thermocouple Type 


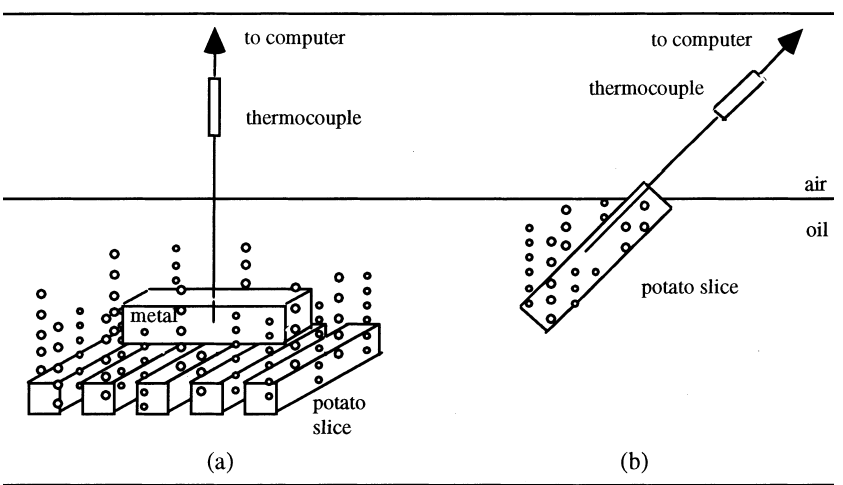

Fig. 1. Schematic representation of the experimental set-up used to measure the heat transfer coefficient: (a) indirect method; (b) direct method.

$\mathrm{K}$ (Omega Engineering, Connecticut, USA) and acquired into a 286 PC with an acquisition board (PCLD 889, Advantech, Taipei, Taiwan). The $h$ value was determined by application of Newton's law (Holman, 1990):

$\frac{T_{\mathrm{m}}-T_{\mathrm{o}}}{T_{\mathrm{mi}}-T_{\mathrm{o}}}=\exp \left(-\frac{h A_{\mathrm{m}}}{\rho_{\mathrm{m}} V_{\mathrm{m}} c_{\mathrm{p}_{\mathrm{m}}}} t\right)$

where $A_{\mathrm{m}}$ is the surface area of the metal piece in $\mathrm{m}^{2}, c_{\mathrm{p}_{\mathrm{m}}}$ the specific heat of the metal $\left(460 \mathrm{~J} \mathrm{~kg}^{-1} \mathrm{~K}^{-1}\right), t$ the time in $\mathrm{s}, T_{\mathrm{m}}$ the temperature of the metal piece at time $t$ in ${ }^{\circ} \mathrm{C}$, $T_{\mathrm{mi}}$ the initial temperature of the metal piece in ${ }^{\circ} \mathrm{C}, T_{\mathrm{o}}$ the oil temperature in ${ }^{\circ} \mathrm{C}, V_{\mathrm{m}}$ the volume of the metal piece in $\mathrm{m}^{3}$ and $\rho_{\mathrm{m}}$ the density of the metal $\left(7850 \mathrm{Kg} \mathrm{m}^{-3}\right)$.

The Biot number was found to be between 0.0068 and 0.023 , thus in the range where Eq. (1) is valid. Fig. 2a shows typical heating curves and the fit of Eq. (1) to the experimental data.

\subsection{Direct method of estimation of the $h$ value}

One potato slice with the desired geometry was immersed with a thermocouple $(0.50$ or $0.75 \mathrm{~mm}$ diameter

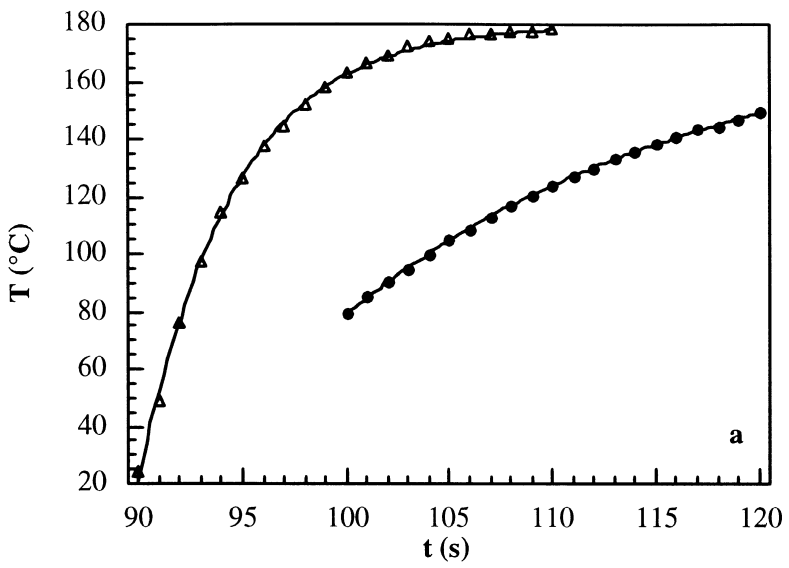

thermocouple Type J-Omega, CT, USA) inserted within the potato, approximately $0.3 \mathrm{~mm}$ below the surface. The potato slice was not completely immersed in the frying medium in order to avoid errors in the temperature measurements caused by conduction heating, which would occur if the thermocouple was in direct contact with the oil (this was not necessary in the indirect method, as the conduction heating of the thermocouple was negligible because of the high heating rate of the metal piece). However, the point of the potato where the temperature was measured was well inside the frying medium (see Fig. 1b). Three replicates were performed. Temperature was monitored and recorded in a computer. Typical heating curves are shown in Fig. 2b.

The $h$ value was calculated assuming that the total heat transferred by convection from the oil to the potato surface is used both for heating the potato, $Q_{\mathrm{h}}$, and for water evaporation, $Q_{\mathrm{e}}$ :

$Q_{\mathrm{h}}=\gamma Q_{\mathrm{T}}=\gamma A_{\mathrm{p}} h\left(T_{\mathrm{s}}-T_{\mathrm{o}}\right)$,

$Q_{\mathrm{e}}=(1-\gamma) Q_{\mathrm{T}}=(1-\gamma) A_{\mathrm{p}} h\left(T_{\mathrm{s}}-T_{\mathrm{o}}\right)=\lambda \dot{w}$,

where $A_{\mathrm{p}}$ is the potato surface area in $\mathrm{m}^{2}, Q_{\mathrm{T}}$ the total heat transferred from the oil to the potato in $\mathrm{J} \mathrm{s}^{-1}, T_{\mathrm{s}}$ the temperature at the potato surface in ${ }^{\circ} \mathrm{C}, \dot{w}$ the water loss rate in $\mathrm{kg} \mathrm{s}^{-1}, \gamma$ the fraction of $Q_{\mathrm{T}}$ used for potato heating and $\lambda$ the latent heat $\left(2257 \mathrm{~kJ} \mathrm{~kg}^{-1}\right.$ at $100^{\circ} \mathrm{C}-$ Perry, Green and Maloney, 1984).

The heat transfer coefficient may be obtained by adding $\gamma h$ to $(1-\gamma) h$. The latter is easily calculated from Eq. (3):

$(1-\gamma) h=\frac{\lambda \dot{w}}{A_{\mathrm{p}}\left(T_{\mathrm{s}}-T_{\mathrm{o}}\right)}$

using for each time the corresponding temperature at the potato surface and the water loss rate determined experimentally.

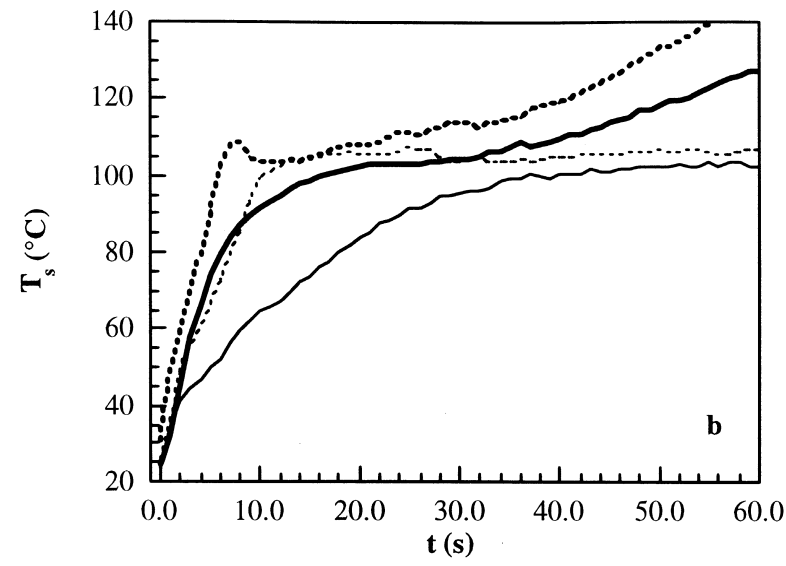

Fig. 2. Typical heating curves. indirect method: $(\triangle)$ Crisps at $180^{\circ} \mathrm{C} ;(\bullet)$ French fries at $180^{\circ} \mathrm{C}$ (the lines represent the fit of Eq. (1)). (b) Direct method: $(--)$ French fries at $140^{\circ} \mathrm{C} ;(\square)$ French fries at $180^{\circ} \mathrm{C} ;(-\ldots----)$ Crisps at $140^{\circ} \mathrm{C} ;(\ldots \ldots \ldots)$ Crisps at $180^{\circ} \mathrm{C}$. 
The average value of $\gamma h$ between time 0 and time $t, \gamma \bar{h}$, can be obtained from the solution of Fourier's 2nd law, assuming initial uniform temperature and convection at the boundary. Crisps can be considered as plane sheets and thus the solution of Fourier's 2nd law can be applied (Crank, 1975):

$\frac{T_{\mathrm{s}}-T_{\mathrm{o}}}{T_{\mathrm{si}}-T_{\mathrm{o}}}=\sum_{n=1}^{\infty} \frac{2 L^{2} \cos \left(\beta_{n}^{2}\right) \exp \left(-\beta_{n}^{2} \alpha t / l^{2}\right)}{\left(\beta_{n}^{2}+L^{2}+L\right) \cos \beta_{n}}$,

where $L=l \gamma \bar{h} / k_{\mathrm{p}}, \alpha=k_{\mathrm{p}} / \rho_{\mathrm{p}} c_{\mathrm{p}_{\mathrm{p}}}, \beta_{n} \tan \beta_{n}=L, l$ is the halfthickness in $\mathrm{m}, c_{\mathrm{p}_{\mathrm{p}}}$ the potato specific heat in $\mathrm{J} \mathrm{kg}^{-1} \mathrm{~K}^{-1}$, $k_{\mathrm{p}}$ the potato heat conductivity in $\mathrm{W} \mathrm{m}^{-1} \mathrm{~K}^{-1}, T_{\mathrm{s}}$ the potato surface temperature at time $t$ in ${ }^{\circ} \mathrm{C}, T_{\text {si }}$ the initial potato surface temperature in ${ }^{\circ} \mathrm{C}$ and $\rho_{\mathrm{p}}$ the potato density. Although thermal conductivity and specific heat change with temperature and, especially, with water content, changes in thermal diffusivity $(\alpha)$ are minor (Rice, Selman \& Abdul-Reezzak, 1988). The potato specific heat, $4036 \mathrm{~J} \mathrm{~kg}^{-1} \mathrm{~K}^{-1}$, was estimated using a correlation reported by Wang and Brennan (1993) that relates this parameter with temperature and moisture content. The calculations were based on the initial moisture content and on a temperature of $100^{\circ} \mathrm{C}$. In terms of potato heat conductivity, a value of $0.56 \mathrm{~W} \mathrm{~m}^{-1}$ $\mathrm{K}^{-1}$. The density value of the raw potatoes, determined experimentally, was $1079 \pm 26 \mathrm{~kg} \mathrm{~m}^{-3}$ and also assumed constant.

For French-fries, Newman's rule (Newman, 1936) was applied. The value of $\gamma h$ for each time $t$, was calculated from its average value, $\gamma \bar{h}$, as follows (Crank, 1975):

$\gamma h=\gamma \bar{h}+\frac{\mathrm{d}(\gamma \bar{h})}{\mathrm{d} t}\left(t-t_{\mathrm{i}}\right)$.

This approach is only valid until the water loss rate reaches a maximum. After this time the surface is dried and water loss is not heat-transfer limited. Thus, only frying times before reaching this point were used to estimate the $h$ value. Because these periods would be extremely small for crisps and for French-fries at $180^{\circ} \mathrm{C}$, the $h$ value was calculated only for French-fries at $140^{\circ} \mathrm{C}$.

\subsection{Water loss rate}

The water loss rate was obtained using an image analysis method, as described elsewhere (Costa et al., 1997).

\section{Results and discussion}

During frying only nucleate boiling is observed. Water vapour bubbles are formed at the various surfaces of the potato samples and flow upwards, towards the top of the frying bath. It was observed that the bubbles leaving from the top surface go up immediately after formation, having a great influence on oil agitation. The bubbles leaving from the sidewalls flow up next to the wall, promoting a different type of agitation. Finally, bubbles that leave the down-faced surface coalesce before flowing against the potato surface to the edges, and then to the top along the side surfaces. Thus, the heat transfer coefficient $(h)$ may be expected to be position dependent, and while at the top surface agitation may increase the $h$ value, the opposite may happen in the lower surface, as the big water vapour bubbles may lead to a increased resistance to heat transfer. In addition, during frying, the potato samples geometry change, particularly in crisps, changing the oil agitation patterns. These differences cannot, however, be analysed with our results, as we have measured only an average $h$ value along frying. Furthermore, the bubbles flow out of the potato, whereas in the indirect method, they flow towards the metal piece (which unavoidably also changes somehow the bubbles flow), and changes in the $h$ value around the potato samples, due to their change of size and geometry along frying are not reflected in the $h$ value measured for the metal pieces. In the direct method, the water loss rate values are an average for the whole potato sample and the $h$ value could only be measured for short times. Thus, the $h$ values reported in this work should be seen as an average indication and not as a specific measure of the $h$ value near any of the potato surfaces. Although this is a limitation, the results provide some insight into the $h$ value changes during frying and should be much closer to the reality than most of the values used in the literature, that do not account for the effect of vapour bubbling.

Figs. 3 and 4 show the evolution of the $h$ value (obtained by the indirect method) and of the water loss rate. The coefficients of variation of the $h$ values averaged $8.5 \%$ and $10 \%$, respectively, for the indirect and direct method. It can be seen that the $h$ value increases with time up to a maximum value $\left(594 \pm 38 \mathrm{~W} \mathrm{~m}^{-2} \mathrm{~K}^{-1}\right.$ at $140^{\circ} \mathrm{C}$ and $750 \pm 59 \mathrm{~W} \mathrm{~m}^{-2} \mathrm{~K}^{-1}$ at $180^{\circ} \mathrm{C}$, for crisps; $443 \pm 32 \mathrm{~W} \mathrm{~m}^{-2} \mathrm{~K}^{-1}$ at $140^{\circ} \mathrm{C}$ and $650 \pm 7 \mathrm{~W} \mathrm{~m}^{-2} \mathrm{~K}^{-1}$ at $180^{\circ} \mathrm{C}$, for French-fries) and then decreases. The time at which this maximum was observed shows a delay in relation to the time when maximum water loss rate is reached (see Figs. 3 and 4). The direct method also showed a maximum with time, although this maximum was noticed earlier and slightly before the maximum water loss rate was reached (Fig. 5). This shows that the vapour bubbles formed at the potato surface when the water loss rate is very high may actually present an additional resistance to heat transfer and thus decrease the $h$ value. The maximum $h$ value was greater than that measured with the indirect method (app. $440 \mathrm{~W} \mathrm{~m}^{-2} \mathrm{~K}^{-1}$ for French fries at $140^{\circ} \mathrm{C}$ ), showing that the latter method may underpredict the $h$ values. At the end of 

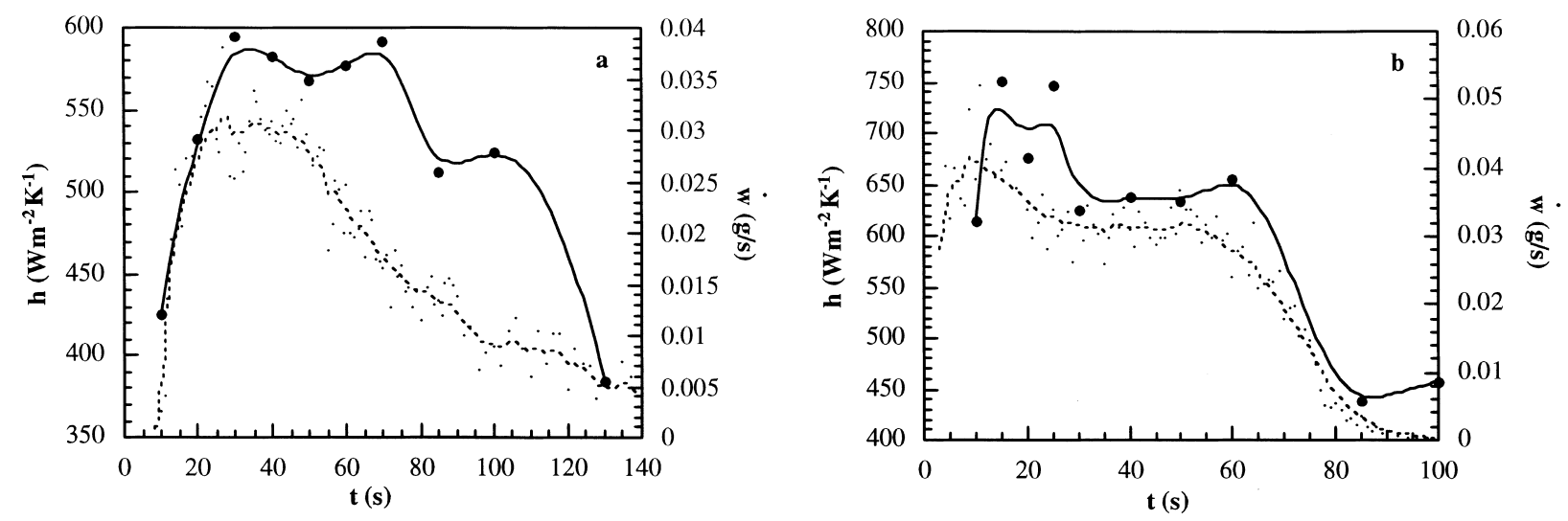

Fig. 3. Heat transfer coefficient measured with the indirect method $(\bullet)$ and water loss rate ( ) changes during frying of crisps: (a) $140^{\circ} \mathrm{C}$; (b) $180^{\circ} \mathrm{C}($ the lines represent a smooth fit).
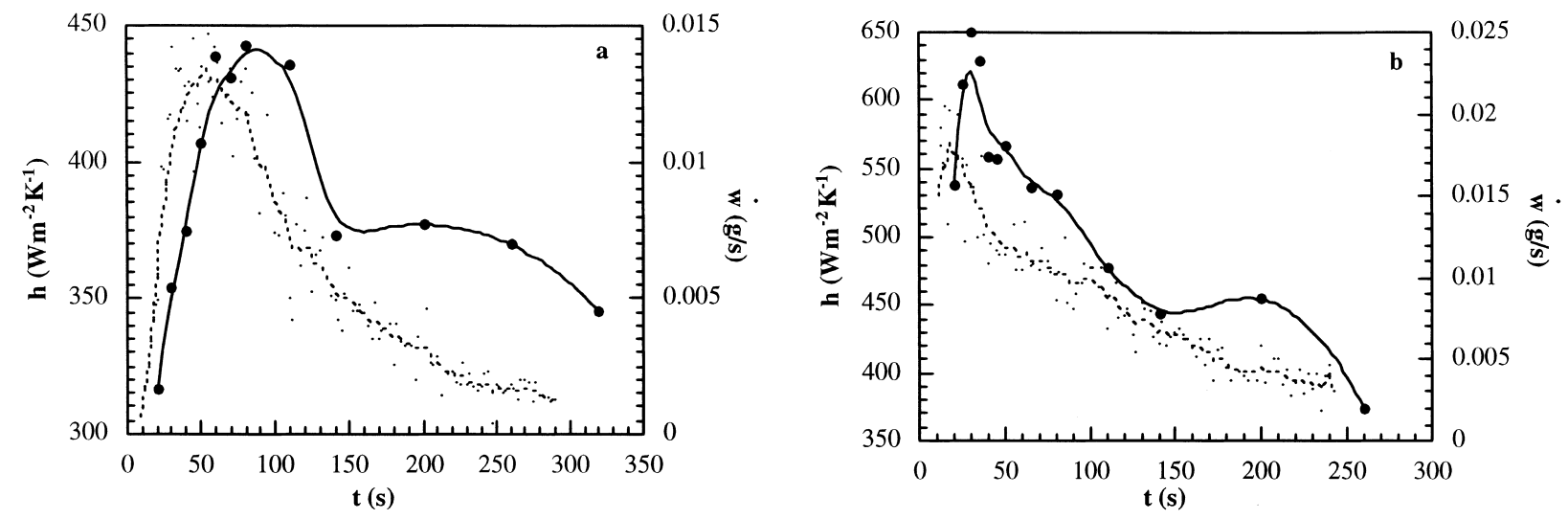

Fig. 4. Heat transfer coefficient measured with the indirect method $(\bullet)$ and water loss rate ( ) changes during frying of French-fries: (a) $140^{\circ} \mathrm{C}$; (b) $180^{\circ} \mathrm{C}$ (the lines represent a smooth fit).

frying the $h$ values obtained by the indirect method were similar to those measured in the absence of bubbling: $436 \pm 40 \mathrm{~W} \mathrm{~m}^{-2} \mathrm{~K}^{-1}$ at $140^{\circ} \mathrm{C}$ and $416 \pm 27 \mathrm{~W} \mathrm{~m}^{-2} \mathrm{~K}^{-1}$ at $180^{\circ} \mathrm{C}$, for crisps, and $353 \pm 32 \mathrm{~W} \mathrm{~m}^{-2} \mathrm{~K}^{-1}$ at $140^{\circ} \mathrm{C}$

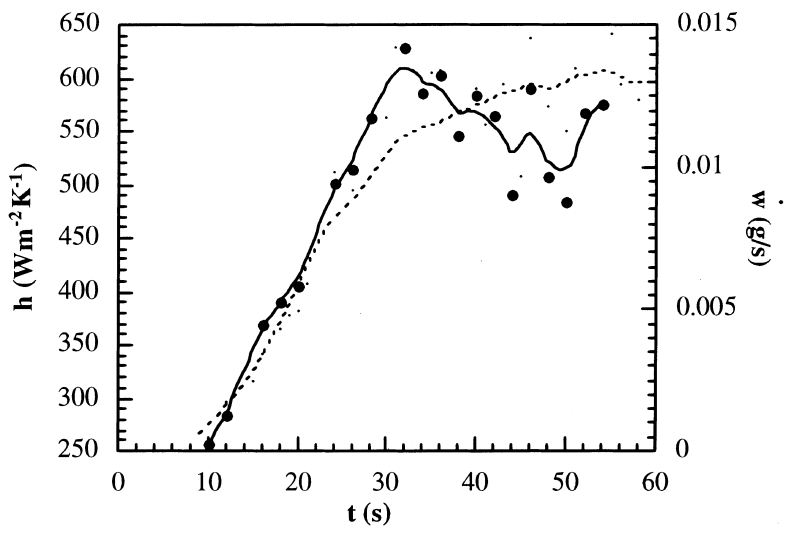

Fig. 5. Heat transfer coefficient measured with the direct method $(\bullet)$ and water loss rate (') changes during frying of French-fries at $140^{\circ} \mathrm{C}$ (the lines represent a smooth fit). and $389 \pm 15 \mathrm{~W} \mathrm{~m}^{-2} \mathrm{~K}^{-1}$ at $180^{\circ} \mathrm{C}$ for French-fries. These values are somewhat higher than those reported in the literature (Miller et al., 1994; Tseng et al., 1996), probably because of the mechanical agitation used in the frying bath. The experiments at $180^{\circ} \mathrm{C}$ show higher $h$ values, as might be expected because of the higher water loss rates and the effect of temperature on viscosity (Miller et al., 1994). The effect of bubbling on the $h$ value appears to be more pronounced at $180^{\circ} \mathrm{C}$, as maximum $h$ values are $80 \%$ greater than those obtained without bubbling, whereas at $140^{\circ} \mathrm{C}$ this increase corresponds to $40 \%$ only. The $h$ values are on average app. $30 \%$ greater for crisps, when compared to French fries; this effect may be partly due to geometry effects, as a $10 \%$ difference is found even in the absence of bubbling, but the effects of water loss rates and frying agitation patterns are also important.

Fig. 6 shows the dependency of the ratio between the $h$ value during frying and the $h$ value without bubbling on the water loss rate (results obtained by the indirect method). Although the data show a large scatter, an increase with water loss rate is visible. This increase may 


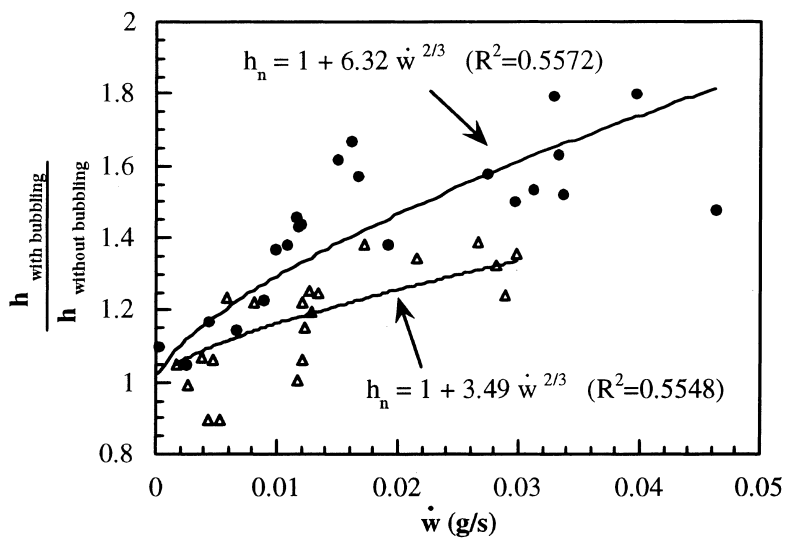

Fig. 6. Relationship between the heat transfer coefficient (measured with the indirect method) normalised in respect to the corresponding value without bubbling and water loss rate: $(\triangle) 140^{\circ} \mathrm{C} ;(\bullet) 180^{\circ} \mathrm{C}$.

be described as proportional to $\dot{w}^{2 / 3}$, as Kutateladze (1979) observed for bubbling phenomena, analysing the heat transfer from a microporous surface in bubbling gas through liquid. The effect of the water loss rate is more pronounced at $180^{\circ} \mathrm{C}$, as earlier concluded. The potato geometry did not affect this relationship, whereas the normalised $h$ value was in general higher for $180^{\circ} \mathrm{C}$, even for the same water loss rate. Thus, one may conclude that the lower oil viscosity at $180^{\circ} \mathrm{C}$ may also decrease the resistance of the oil to the agitation caused by the vapour bubbles, thus promoting a higher turbulence. The direct method (Fig. 7) also shows an increase of the $h$ value with water loss rate. The data show less scatter and the increase is linear with $\dot{w}$ rather than with $\dot{w}^{2 / 3}$, but the range of water loss rate analysed in this case was smaller.

The evolution of the fraction of heat used for evaporation during frying at $140^{\circ} \mathrm{C}$ is shown in Fig. 8. One can see that both the direct and indirect method yield similar results and that $1-\gamma$ rises with time, tending to

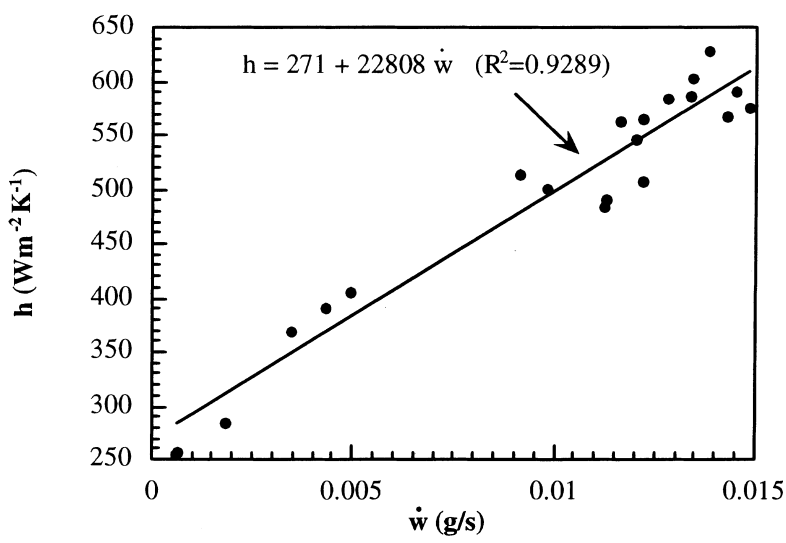

Fig. 7. Relationship between the heat transfer coefficient (measured with the direct method) and water loss rate during frying of French fries at $140^{\circ} \mathrm{C}$.

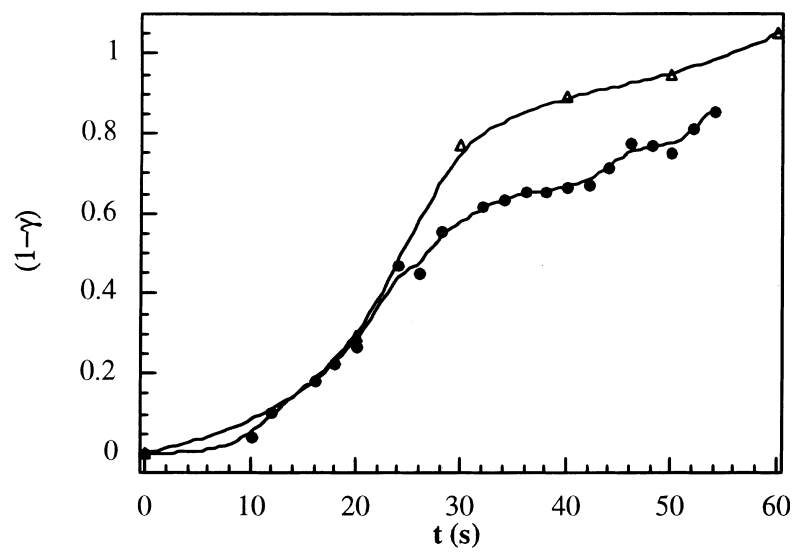

Fig. 8. Evolution of the fraction of total heat used for evaporation $(1-\gamma)$ during frying of French fries at $140^{\circ} \mathrm{C}: \triangle$ indirect method; $\bullet$ direct method (the lines represent a smooth fit).

level off as the potato surface approaches the evaporation temperature (app. $103^{\circ} \mathrm{C}$ ). The fraction of heat used for evaporation depends on (i) the temperature gradient between the potato surface and the heating medium, (ii) the water loss rate and (iii) the $h$ value (that in turn depends on the water loss rate). Combining Eq. (4) with the equation presented in Fig. 7, one can predict the influence of the water loss rate and the temperature gradient on the fraction of heat used for evaporation, $1-\gamma$ :

$1-\gamma=\frac{\lambda}{A_{\mathrm{p}}} \frac{\dot{w}}{(271+22803 \times \dot{w})\left(T_{\mathrm{o}}-T_{\mathrm{s}}\right)}$.

\section{Conclusions}

The $h$ values determined in frying were up to two times greater than those obtained in the absence of vapour bubbling and vary with the water loss rate, showing a maximum close to the time when the maximum water loss rate is reached. Although the oil movement caused by the bubbles promotes increased heat transfer rates, there was some evidence that when the water loss rate is very high the bubbles near the potato surface may hinder the heat transfer. The percentage of heat transferred to the potato that is used for water evaporation increases with time while the water loss is heat controlled.

\section{Acknowledgements}

The first author acknowledges financial support from Fundação para a Ciência e a Tecnologia (FCT) through "Sub-programa Ciência e Tecnologia do $2^{\circ}$ Quadro Comunitário de Apoio". 


\section{References}

Burmeister, L. C. (1983). Boiling. In L. C. Burmeister, Convective heat transfer (pp. 576-629). Toronto: John Wiley \& Sons.

Costa, R. M., Oliveira, F. A. R., \& Gekas, V. (1997). Application of image analysis to the study of water losses from potato slices during frying. In R. Jowitt, Engineering \& food at ICEF 7, Part I (pp. A157-A160). Sheffield: Sheffield Academic Press.

Crank, J. (1975). In The mathematics of diffusion (2nd ed.). Bristol: Oxford University Press.

Farkas, B. E. (1994). Modelling immersion frying as a moving boundary problem, Ph.D. Thesis. Davis, USA: University of California.

Fellows, P. J. (1996). Food processing technology - Principles and practice (2nd ed., pp. 331-332). Cambridge: Woodhead Publishing Limited.

Holman, J. P. (1990). Unsteady state heat conduction. Heat transfer (6th ed., pp. 131-206). New York: McGraw-Hill Book.

Hubart, J. L., \& Farkas, B. E. (1998). Determination of the convective heat transfer coefficient during immersion frying. In C. B. Aktridis, D. Marinos-Kouris, \& G. D. Saravakos, Drying'98, vol. A (pp. 781-788). Thessaloniki: Ziti Editions.

Kutateladze, S. S. (1979). Boiling and bubbling heat transfer under free convection of liquid. International Journal of Heat and Mass Transfer, 22, 281-299.
Miller, K. S. (1992). Physical and thermal properties of edible frying oils, M.Sc. Thesis. Davis, USA: University of California.

Miller, K. S., Singh, R. P., \& Farkas, B. E. (1994). Viscosity and heat transfer coefficients for canola, corn, palm, and soybean oil. Journal of Food Processing and Preservation, 18, 461-472.

Mohsenin, N. N. (1986). Physical properties of plant and animal materials (p. 101). New York: Gordon and Breach Science Publishers.

Newman, A. B. (1936). Heating and cooling rectangular and cylindrical solids. Industrial and Engineering Chemistry, 28, 545-548.

Perry, R. H., Green, D. W., \& Maloney, J. O. (1984). Perry's chemical engineers' handbook (5th ed., pp. 3-239). Singapore: McGraw-Hill.

Rice, P., Selman, J. D., \& Abdul-Reezzak, R. K. (1988). Effect of temperature on thermal properties of 'Record' potatoes. International Journal of Food Science and Technology, 23, 281-286.

Tseng, Y. C., Moreira, R., \& Sun, X. (1996). Total frying-use time effects on soybean-oil deterioration and on tortilla chip quality. International Journal of Food Science and Technology, 31, 287-294.

Wang, N., \& Brennan, J. G. (1993). The influence of moisture content and temperature on the specific heat of potato measured by differential scanning calorimetry. Journal of Food Engineering, 19, 303-310. 